\title{
The Drivers of Inflation in a Small Open European Economy: The Case of Romania
}

\author{
Raluca-Elena Pop and Bogdan Murarașu
}

\begin{abstract}
This paper uses a Bayesian VAR model to quantify the contribution of domestic and global shocks in driving inflation in Romania in the period after the adoption of the inflation targeting monetary policy regime, with a particular focus on the low inflation period that characterized the recent years. The results suggest that both domestic and global shocks have played important roles in shaping the dynamics of inflation. However, in the context of the increasingly significant presence of global value chains in the local market and the higher contribution from imported goods to covering domestic consumption, the low inflation rates observed since the mid-2013 seem to be to a larger extent driven by global factors.
\end{abstract}

Index Terms-Bayesian vector autoregression, inflation dynamics, shock identification.

\section{INTRODUCTION}

Inflation in Romania was a major issue during the 1990s, with a peak of $256 \%$ in 1993 . Since then the inflation has slowly decrease, being brought to a single digit level at the end of 2004. The introduction of an inflation targeting monetary policy regime by the National Bank of Romania in august 2005 has further enhanced this process. [1] present a detailed discussion about the inflation dynamics and its determinants in Romania in the 1990s and the years before the global and financial crisis of 2007-2008. Since mid-2013, in line with the trend manifested on the international front, the annual CPI inflation rate stood at historical low levels, even excluding the first round effects of VAT rate cuts in September 2013, June 2015 and January 2016 (Fig. 1).

In this paper a Bayesian vector autoregression (VAR) model is used to quantify the role played by domestic and global factors in driving inflation in Romania in the period after the adoption of the inflation targeting monetary policy regime, with a particular focus on the low inflation period. The identification of the shocks is based on Cholesky factorization.

The results suggest that the low inflation rates observed since the mid-2013 are to a larger extent driven by global factors. The higher relative importance of external environment in determining the path of the inflation rate in recent years may be attributed to the increasingly significant presence of global value chains (for example, large retailers), but also to the increasingly higher contribution from imported goods to covering domestic consumption.

Manuscript received January 25, 2018; revised March 12, 2018

Raluca-Elena Pop is with the Bucharest University of Economic Studies, Economic Cybernetics and Statistics Doctoral School, Bucharest, Romania (e-mail: pop_ralucaelena@yahoo.com).

Bogdan Murarașu is with the Bucharest University of Economic Studies, Money and Banking Department, Bucharest, Romania (e-mail: bogdan.murarasu@fin.ase.ro).

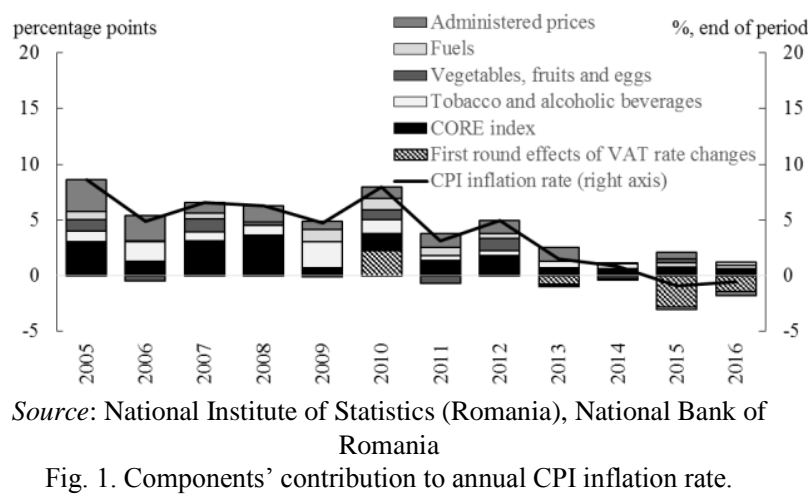

The remainder of the paper is organized as follows: in section II an overview of the related literature is provided. Section III describes data and methodology. Section IV reports the results and, finally, section $\mathrm{V}$ concludes.

\section{RELATED LITERATURE}

Over the past years the impact of globalization on the inflation development has received a lot of attention in the economic literature, also in the context of the decoupling between price dynamics and economic growth that could be observed after the outbreak of the international economic and financial crisis of 2007-2008. During the Great Recession the inflation was rather resilient given the large fall in output. This so-called "missing-disinflation" puzzle was documented, among others, by [2] for the US and [3] for other advanced economies. Since 2012, a "missing-inflation" puzzle has emerged, characterized by a global disinflationary environment, despite the gradual recovery in the economic activity worldwide.

The issue regarding the flattening of the Phillips curve, that formalizes the relation between inflation and real activity, was raised by several authors as a possible explanation to this twin puzzle. The results are rather mixed. According to [4], over the past decade the inflation in advanced economies has become less responsive to changes in economic slack. [5] find similar evidence by estimating the Phillips curve equation for 11 OECD countries for the period 1977-2005. The same conclusion is drawn by [6]. They analyze the slope of the Phillips curve for 16 developed countries and the euro area starting from 1972 and identify the globalization as the main factor for the decline in the sensitivity of prices to output gap. However, [7] analyze the Phillips curve relation over the past 50 years for 20 countries and find that the slope of the Phillips curve has decreased until the early 1990s, but has remained roughly stable since then. Also the empirical evidence provided by [8] for euro area and US economies does not support the hypothesis of a change in the slope of the Phillips curve after the Great Recession. In case of Romania 
the econometric estimations of the Phillips curve performed by [9] indicate a declining trend in core inflation sensitivity to output gap in the last 3 years.

Another line of research argues that inflation has become a global phenomenon, i.e. it has become more sensitive to economic developments abroad. [10] show that nearly 70 percent of inflation variability in 22 OECD countries is being driven by one common global factor. They document a robust sensitiveness of the estimated global factor to real and monetary determinants measured at global level. [11], using a panel of 164 series for the most industrialized economies in the world, also present evidence that the international component of national inflations has become increasingly more important in the last decade. These recent results are in contradiction with the ones presented by [12] who concludes that the flattening of the Phillips curve, documented for the G7 countries for the period 1971-2005, is not the result of foreign trade, i.e. it is not caused by the phenomenon of globalization.

The methodologies applied by the broad strand of literature investigating the determinants of inflation vary from small-reduced form models (e.g. [13], [14]) to structural VAR models (e.g. [8], [15]) and structural dynamic stochastic general equilibrium models (e.g. [16], [17]).

\section{DATA AND METHODOLOGY}

In order to disentangle between various shocks behind inflation dynamics in Romania, the historical decomposition based on a structural VAR model is used. As [8] emphasize, this methodology is flexible enough to properly identify the global and domestic factors affecting inflation and to capture their changing relative importance over time.

The general form of a structural VAR model of order $l$ is:

$$
D y_{t}=A_{0}+A_{1} y_{t-1}+A_{2} y_{t-2}+\cdots+A_{l} y_{t-l}+u_{t}
$$

where $t=1,2, \ldots, T \cdot y_{t}=\left(y_{1 t}, y_{2 t}, \ldots, y_{n t}\right)^{\prime}$ is a $n \times 1$ vector of observable variables, $A_{0}$ is a $n \times 1$ vector of constant terms, $D, A_{1}, A_{2}, \ldots, A_{l}$ are $n \times n$ matrices of coefficients and $u_{t}=\left(u_{1 t}, u_{2 t}, \ldots, u_{n t}\right)^{\prime}$ denotes an unobservable $n$-dimensional vector of structural innovations, following a multivariate normal distribution, i.e. $u_{t} \sim N(0, \Sigma)$. $n$ represents the number of observable variables and $\mathrm{T}$ is the size of the estimation sample.

Assuming that $D^{-1}$ exists, the time-series process can be written as:

$$
\begin{gathered}
y_{t}=D^{-1} A_{0}+D^{-1} A_{1} y_{t-1}+D^{-1} A_{2} y_{t-2}+\cdots \\
\quad+D^{-1} A_{l} y_{t-l}+D^{-1} u_{t} \\
y_{t}=B_{0}+B_{1} y_{t-1}+B_{2} y_{t-2}+\cdots+B_{l} y_{t-l}+\varepsilon_{t}
\end{gathered}
$$

where $\operatorname{cov}\left(\varepsilon_{t}\right)=E\left(\varepsilon_{t} \varepsilon_{t}^{\prime}\right)=\Omega$. Equation (3) is a VAR model of order $l$ that can be thought of as a reduced form of the structural model (1) and can be estimated directly from the data using, for example, ordinary least squares method. The reduced-form residuals, $\varepsilon_{t}=D^{-1} u_{t}$, are linear combinations of the structural shocks $u_{t}$ in (1), only the latter having an economic interpretation.

The analyzed period corresponds to the inflation targeting monetary policy regime (2005 Q3 - 2017 Q2). However, the sample used for estimation is larger (2001 Q1 - 2017 Q2) in order to allow for the impact of the initial observations to abate in the historical decomposition.

The variables included in the specification are:

- The price of oil;

- An effective EU GDP measure, as a proxy for global demand. The measure is calculated using a weighting system that takes into account the breakdown of Romania's intra-EU exports by destination and accounts for approximately $75 \%$ of Romania's exports;

- The euro area HICP index excluding energy, as a proxy for imported inflation;

- The domestic GDP;

The domestic CPI index excluding regulated prices and the first-round effects of VAT rate changes. It is the common view of theoreticians and practitioners that the dynamics of administered prices mainly depend on exogenous factors and, therefore, they can distort the results of the estimations based on CPI index, especially if they have an important contribution to the consumer basket (in Romania administered prices account for approximately $19 \%$ of the basket). The same holds true for the changes in taxation. During the analyzed period, Romania experienced several VAT rate changes, with a substantial impact on CPI inflation: an increase in the standard VAT rate from 19 percent to 24 percent as from 1 July 2010 (first-round effect of 2.2 percentage points on the annual CPI inflation rate, source: National Bank of Romania's Inflation Reports), a cut in the VAT rate applied to flour and bread to 9 percent as of 1 September 2013 (-0.8 percentage points), a lowering of the VAT rate to 9 percent for all food items, non-alcoholic beverages and public food services as of 1 June 2015 (-2.8 percentage points), a cut in the standard VAT rate from 24 percent to 20 percent as from 1 January 2016 (-1.4 percentage points) and a cut in the standard VAT rate from 20 percent to 19 percent as from 1 January 2017 (-0.3 percentage points);

- 3-month Robor interest rate;

- The EUR/RON exchange rate. The exchange rate is defined so that an increase is equivalent with a depreciation.

With the exception of the interest rate, all the other variables are expressed in annual changes. As is the common practice in quarterly VARs, four lags of the endogenous variables are included in the specification.

Some restrictions are required on any (or all) of the structural parameters in order to recover the structural parameters in (1) from the estimated VAR model in (3) uniquely. One of the most common approach is the use of the Choleski identification scheme, which imposes a recursive form for the structural model, i.e. a causal chain for the variables included in the model specification. For the particular case considered here the restrictions are presented in Table I. The first three shocks refer to the external environment and the subsequent two shocks are domestic. A monetary policy shock is also identified and an exchange rate shock. The external variables are ordered first, i.e. global variables affect domestic variables immediately. Moreover, a block exogeneity restriction is imposed in order to account for the small open economy feature of Romania, i.e. the shocks originating in the external sector are allowed to influence the internal variables, but not the other way around. 
The ordering of domestic variables implies that the monetary policy shock doesn't have a contemporaneous impact on policy variables (GDP growth and inflation). A similar approach for identifying the monetary policy shock is used, for example, by [18]. Following [8], the exchange rate shock is interpreted as a residual shock, which accounts for the fluctuations of exchange rate not explained by the previous shocks and does not contemporaneously affect any of the other variables.

Taking into account the short data sample available, in order to improve the robustness of the results, the estimation of the model is done in a Bayesian framework. The principle of Bayesian analysis is to combine any prior information that is available regarding the possible distribution of the parameters of interest (the prior distribution), for example from the economic literature, with the information contained in the data (and summarized with the help of the likelihood function), in order to obtain an updated distribution which takes into account both sources of information, known as the posterior distribution. There is a wide variety of prior distributions proposed in the economic literature to choose from: Minnesota prior, Normal-diffuse prior, Normal-Wishart prior, independent Normal-Wishart prior etc. The one considered in this paper is the independent Normal inverse Wishart prior which is more flexible in terms of the restrictions imposed, but implies the sacrifice of analytical solutions in favor of numerical methods, which are more time and resource consuming.

TABLE I: IDENTIFICATION RESTRICTIONS

\begin{tabular}{cccccccc}
\multicolumn{7}{c}{ TABLE I: IDENTIFICATION RESTRICTIONS } \\
\hline $\begin{array}{cccccc}\text { Shock/ } \\
\text { Variable }\end{array}$ & $\begin{array}{c}\text { Price } \\
\text { of oil }\end{array}$ & $\begin{array}{c}\text { External real } \\
\text { GDP }\end{array}$ & $\begin{array}{c}\text { External } \\
\text { prices }\end{array}$ & $\begin{array}{c}\text { Domestic } \\
\text { real GDP }\end{array}$ & $\begin{array}{c}\text { Domestic } \\
\text { prices }\end{array}$ & $\begin{array}{c}\text { Short-term } \\
\text { interest rate }\end{array}$ & $\begin{array}{c}\text { Exchange } \\
\text { rate }\end{array}$ \\
\hline Global & + & $?$ & $?$ & $?$ & $?$ & $?$ & $?$ \\
Gilobal & 0 & + & $?$ & $?$ & $?$ & $?$ & $?$ \\
Gilobal & 0 & 0 & + & $?$ & $?$ & $?$ & $?$ \\
$\begin{array}{c}\text { Domestic } \\
\text { Domestic }\end{array}$ & 0 & 0 & 0 & + & $?$ & $?$ & $?$ \\
$\begin{array}{c}\text { Monetary } \\
\text { policy }\end{array}$ & 0 & 0 & 0 & 0 & + & $?$ & $?$ \\
Exchange & 0 & 0 & 0 & 0 & 0 & + & $?$ \\
rate & 0 & 0 & 0 & 0 & 0 & 0 & +
\end{tabular}

Notes: $(+)=$ positive sign restriction, $(0)=$ zero restriction and $(?)=$ unrestricted. All restrictions are imposed on impact.

\section{RESULTS}

Fig. 2 reports the historical decomposition of inflation rate (annual changes of domestic CPI index excluding administered prices and the first-round effects of VAT rate changes). The black line is the difference between the median unconditional forecast generated by the VAR model (obtained under the assumption that there are no shocks during the whole period) and the actual series, while the bars show the contribution of each shock. For an easier interpretation of the results, the contribution of the three global shocks and the two domestic shocks (without the monetary policy shock) respectively were aggregated.

The results suggest that both domestic and global shocks have played important roles in shaping the dynamics of inflation in the analyzed period. The global factors were predominantly in the first two years after the crisis, when the build-up of tensions on the agri-food market and the pronounced upward trend in the international oil price were among the main drivers of inflation dynamics. The historical decomposition also point to a strengthening of the role of external factors in the last years in explaining the dynamics of domestic prices. On one side, the large adjustment of crude oil prices as of mid-2014 was strongly reflected in the domestic prices, particularly via the fuel component. Moreover, substantial indirect effects were passed through to domestic inflation via energy and transportation costs. On the other side, the increase in the relative importance of global factors has also been supported by the higher trade integration with the European Union (the share of trade with the European Union has increased from around 55 percent in 2005 to 75 percent at the end of 2016) and higher contribution from imported goods to covering the expanding domestic consumption (at present around half of the purchaser of consumer goods is accommodated via imports, from around 30 percent in 2009), in the context of increasingly significant presence of global value chains in the local market. The expansion of large foreign retailers in the Romanian market increases the competition in retail area, having a positive impact on price dynamics as it diminishes the pass-through of domestic pressures (for example, coming from wage costs) into prices. Consequently, in the recent years the increase in the relative importance of global factors was accompanied by a weakening relationship between inflation and the domestic environment.

The monetary policy shock had a relative low contribution to inflation dynamics in the analyzed period, especially after the global and financial crisis of 2007-2008, probably in the context of the supplementation of the central banks' traditional monetary policy function by macroprudential policy as a response to the crisis (see [19]).

Finally, the exchange rate shock explains also only a small fraction of the variance of inflation. As mentioned in Section III, this shock is interpreted as a residual shock, which accounts for the fluctuations of exchange rate not explained by the previous shocks.

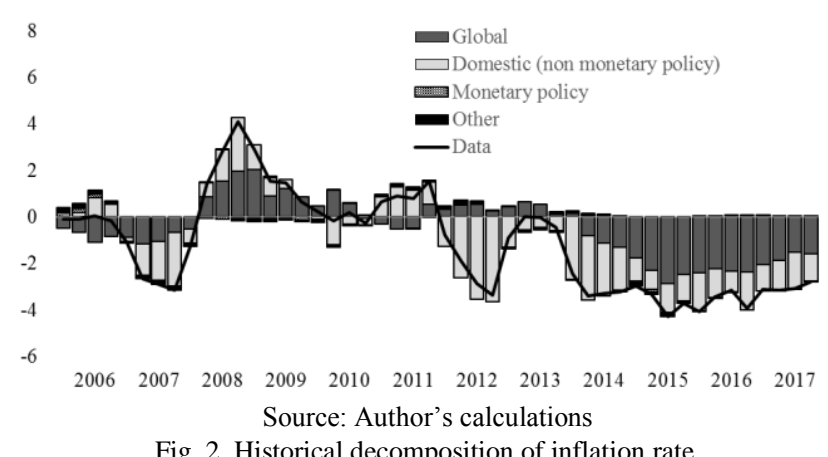

\section{CONCLUSIONS}

Historical decomposition offers a suitable methodological framework for the identification of those shocks which predominantly characterize a particular period. In case of Romania, the results indicate that both domestic and global shocks have played important roles in shaping the price dynamics. However, the low inflation rates observed since the mid-2013 seem to a larger extent to be driven by global factors. This phenomenon is probably related with the higher trade integration with the European Union and the higher contribution from imported goods to covering the expanding domestic consumption.

Although the methodology used is standard in the economic literature, the results should be interpreted with 
caution. The analysis was performed on a relatively small sample of data; also the assumptions of linearity and fixed coefficients can always be questioned, as well as the identification scheme of the structural shocks.

A possible development of the analysis would imply the use of a Bayesian VAR model identified with sign and zero restrictions in order to capture the impact of domestic and global shocks and the changes in the relative importance of these determinants on domestic inflation. In addition, a structural approach based on a DSGE model using a historical decomposition of shocks can add some useful insights in the understanding of fundamental changes in the price formation process.

\section{REFERENCES}

[1] M. Roman and M. Tâlvan, "Tintirea inflației și creșterea economică politici convergente?" Studii şi cercetări de calcul economic şi cibernetică economică, vol. 3/4, pp. 35-49, Autumn 2010.

[2] R. E. Hall, "The long slump," American Economic Review, vol. 101, no. 2, pp. 431-469, January 2011.

[3] C. Friedrich, "Global inflation dynamics in the post-crisis period: What explains the puzzles?" Economics Letters, vol. 142, no. 2, pp. 31-34, May 2016.

[4] IMF, Chapter 3, "The dog that didn't bark: has inflation been muzzled or was it just sleeping?" World Economic Outlook, pp. 1-17, International Monetary Fund, Washington, April 2013.

[5] J. Ihrig, S. B. Kamin, D. Lindner, and J. Marquez, "Some simple tests of the globalization and inflation hypothesis," International Finance, vol. 13 , no. 3, pp. 343-375, Winter 2010

[6] C. Borio and A. Filardo, "Globalisation and inflation: New cross-country evidence on the global determinants of domestic inflation," BIS Working Paper, no. 227, Bank for International Settlements, Basel, May 2007.

[7] O. Blanchard, E. Cerutti, and L. Summers, "Inflation and activity Two explorations, and their monetary policy implications," IMF Working Paper, WP/15/230, November 2015.

[8] E. Bobeică and M Jarocinski, "Missing disinflation and missing inflation: The puzzles that aren't," ECB Working Paper Series, European Central Bank, Frankfurt, January 2017.

[9] NBR, Box 2, "The relationship between economic activity and inflation," Inflation Report, pp. 46-48, National Bank of Romania, Bucharest, May 2017.

[10] M. Ciccarelli and B. Mojon, "Global inflation," The Review of Economics and Statistics, vol. 92, no. 3, pp. 524-535, August 2010.
[11] H. Mumtaz and P. Surico, "Evolving international inflation dynamics: World and country-specific factors," Journal of the European Economic Association, vol. 10, no. 4, pp. 716-734, March 2012.

[12] L. Ball, "Has globalization changed inflation?" NBER Working Paper, no. 12687, National Bureau of Economic Research, United States, November 2006

[13] L. Ball and S. Mazumder, "Inflation dynamics and the great recession," Brookings Papers on Economic Activity, vol. 42, no. 1, pp. 337-405, Spring 2011.

[14] T. Matheson and E. Stavrev, "The great recession and the inflation puzzle," IMF Working Paper, WP/13/124, International Monetary Fund, Washington, May 2013

[15] G. Jovičić and D. Kunovac, "What is driving inflation and GDP in a small European economy: The case of Croatia," HNB Working Papers, no. W-49, Croatian National Bank, Zagreb, April 2017.

[16] M. D. Negro, M. P. Giannoni, and F. Schorfheide, "Inflation in the Great Recession and New Keynesian models," American Economic Journal: Macroeconomics, vol. 7, no. 1, pp. 168-196, January 2015.

[17] L. J. Christiano, M. S. Eichenbaum, and M. Trabandt, "Understanding the Great Recession," American Economic Journal: Macroeconomics, vol. 7, no. 1, pp. 110-167, January 2015.

[18] L. J. Christiano, M. Eichenbaum, and C. L. Evans, "Monetary policy shocks: What have we learned and to what end?" in Handbook of Macroeconomics 1A, J. B. Taylor and M. Woodford, Eds., pp. 65-148, North-Holland, Amsterdam, 1999

[19] B. Vujcic, "Economic and financial cycle spillovers: Reconsidering domestic and cross border channels and policy responses," The National Bank of the Republic of Macedonia, Skopje, April 2016

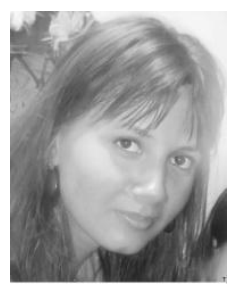

Raluca-Elena Pop is a fourth year PhD student at the Economic Cybernetics and Statistics Doctoral School of Bucharest University of Economic Studies, Romania. Her research interest includes behavioural economics and international macroeconomics. Currently she is working as an economist at the National Bank of Romania, in the Macroeconomic Modelling and Forecasting Department.

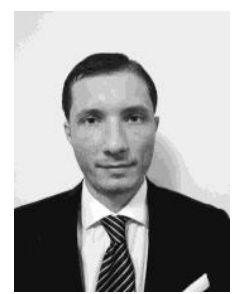

Bogdan Murarașu is an assistant professor at the Bucharest University of Economic Studies, Romania $\mathrm{He}$ has teaching experience in the field of macroeconomic modelling and money and banking. $\mathrm{He}$ is also an experienced economist at the National Bank of Romania. His research is focused on macroeconomic models and inflation forecasting. He holds a Ph.D. in the field of monetary policy at the Bucharest University of Economic Studies. 